\title{
SURVIVOR ACADEME
}

\author{
ASSESSING REFLECTIVE PRACTICE
}

\section{Laurel Johnson Black, Terry Ray, Judith Villa, Indiana University of Pennsylvania}

Reflective practice is a goal for many academic professional development programs. What do faculty participants gain from a reflective practice program, and how much reflection do they actually practice? Using interviews and grounded theory, we identified three crucial needs being met by such a program at our university. In addition, we compared participants' comments to the elements of reflection established by Dewey and Rodgers to determine the extent of their reflection. The results call for more assessment to better align the structures of reflective practice programs with participant needs as well as further research on the effects of reflective practice on the participants, their teaching, and their students.

The vast majority of men live lives of quiet desperation.

-Henry David Thoreau (So, too, do many professors)

Relatively few professors are well prepared for the many aspects of their job that don't focus on research. Isolated in their teaching and stretched thin by demands to publish research in major journals, earn top teaching evaluations, and share the work of university governance, professors often find little time for reflective, intentional teaching. They hover on the edge of burnout, hoping for inspiration. These are needs deeply felt, for they connect to our sense of self-as-teacher; they are not simply a desire for the most recent technology or a better schedule. Indeed, as Mezirow (1990) states, "No need is more fundamentally human than our need to understand the meaning of our experience. Free, full participation 
in critical and reflective discourse may be interpreted as a basic human right" (p. 11).

In response to these needs, programs encouraging reflective practice have sprung up at colleges and universities nationwide. At their best, such programs typically offer long-term support and the opportunity to engage in thoughtful research into pedagogical problems. Fullan (1993) argues that practitioners must "engage in continuous corrective analysis and action" (p. 5) and believes that "if people do not venture into uncertainty, no significant change will occur" (p. 25). Thus, institutions that rely on "teaching tips" or that enforce professional development from the top down do not promote significant and meaningful change. Rather, through both small- and large-group focused study and practice over an extended period of time, using local and national expertise, reflective practice programs support and encourage teachers to question their values and assumptions, test their practices, analyze the results, and continue to improve their teaching. With careful planning and the long-term, sustained support of participants, reflective practice programs can lead to widespread cultural change and involve teachers in discussion of theoretical, political, cultural, and ethical issues, not just teaching techniques (Boud, Keogh, \& Walker, 1985a, 1985b; Lieberman, 1996; McKinnon \& Grunau, 1994; Rodgers, 2002; Szabo, 1996; Schön, 1987).

On paper, reflective practice programs sound good, but do they deliver what they promise? What, in fact, do they promise? Reflective practice, according to Wagner (2006), "will help you celebrate your accomplishments, evaluate your skills, use your strengths more efficiently and continue to set and attain goals" (p. 30). But as Korthagen (1993) points out, given our difficulty in "operationalizing and measuring reflection" (pp. 134-135), how we promote it can become problematic as well: "It is remarkable that no generally accepted definition of the concepts reflection and reflective teaching exists, but also that there is no strong evidence for the claim that the emphasis on reflection is effective. And if it is, one may well ask: effective toward what end? The answer to this question is a matter of belief and conviction rather than one of empirical evidence" (p. 137).

Black, Cessna, and Woolcock (2005) argue that programs as complex as reflective practice usually demand multiple measures of assessment and evaluation. In this chapter, we explore the experiences and attitudes of faculty at one research institution who have participated in a reflective practice program. We support Korthagen's desire for empirical data, but the qualitative data generated by our interviews affords a firm jumpingoff point for additional, more focused research, and a model for other similar programs. 


\section{Assessing Reflective Practice Programs}

Public descriptions of reflective practice programs focus on program structure and history; Indiana University of Pennsylvania's (IUP) program brochure, website, and literature are no exception. However, these texts don't describe what participants actually get from their experience in the program or why they're there. At IUP, we wanted to go beyond the almost-always positive surface descriptions of reflective practice programs. We understand why those descriptions exist-funding for sustained professional development is tough to get and keep, and any data that might suggest that a program isn't producing the results it "should" puts it at risk of being discontinued. It is not too hard for most reflective practice groups to connect tangible outcomes-grants received, articles published, new courses designed-to participation in small groups or workshops. We wanted to get at something else, however, something deeper and more visceral. As Fullan (1993) points out, "[Teachers] function in a complex and dynamic environment where cause and effect are not always clear or close in time" (p. 20). Studying teachers' "intuitionin-action" (p. 361), Johansson and Kroksmark (2004) struggled to go beyond simply describing "the-things-that-show-themselves" and tried to understand how intuition blends experience, action, and emotion. When all is said and done and sixty colleagues have dragged their bodies into a Saturday workshop and stayed all day, why did they do it and what did they get out of it? When a group of five people from different departments meets regularly for a year in a cross-disciplinary discussion of critical thinking, how have they been changed? We decided that, as the first step in a more comprehensive exploration, interviews with current and former members of our reflective practice (RP) program could help us better understand what passions, fears, desires, and needs the RP program at IUP fulfills. Additionally and crucially, it could help us begin to assess its effectiveness in supporting reflection.

It may be that other reflective practice programs are being assessed, but if so, the researchers are keeping quiet about what they find. This is unfortunate, because discussion of multiple, well-designed accountability and evaluation measures of such programs could further the scholarship of teaching and learning and facilitate a productive allocation of scarce resources.

\section{History and Structure of Reflective Practice at IUP}

Indiana University of Pennsylvania is a doctorate-granting research university with approximately twelve thousand students. It has strong roots, however, as a "normal school" with an emphasis on both teaching and 
preparing teachers. IUP established its RP program in 1994 with approximately twenty members in the founding group. Its purpose has always been to encourage faculty to become more aware of their teaching, be more reflective, and through this process become better teachers. The RP project is headed by five co-directors, each having a specific duty within the group. Participation is voluntary and is open to faculty and teaching assistants from the campus doctoral programs. Participants receive no release time or any other institutional reward. Currently, the program offers faculty small-group activities through Departmental and CrossDisciplinary Teaching Circles (DTCs and CTCs), each exploring a topic chosen by its members, monthly large-group meetings addressing various teaching issues, and two or more daylong weekend workshops each year. RP members are asked to attend at least half of the group meetings (whether large group or small group) every year. They are also urged to attend one or more of the weekend workshops, which are open to all faculty. RP has grown dramatically over the past decade, some years numbering more than a hundred members; in 2007-08, approximately seventy faculty actively participated. This number represents roughly 11-15 percent of the faculty. Formal recognition for participation is given in an end-of-the-year dinner when active members receive certificates.

\section{What Reflection Is and How One "Does" Reflective Practice}

Although many readers are familiar with "reflection," it was important for our research to establish what elements we wished to study. The concept of reflective practice is complex and has been defined and interpreted in a variety of ways since Dewey first named it in 1910. According to Rogers (2001), who surveyed and synthesized a range of definitions for reflection and the theories behind them, there is no clear agreement about what it means to be a reflective practitioner or thinker or learner: "In summary, ... no fewer than 15 different terms were used to describe the reflective process" (p. 40). In addition, any reflective practice program must be studied as part of a "systems-thinking approach" that takes into account the "interconnectedness of structures" (Sparks \& Hirsh, 1997, pp. 6-9). RP is supported, after all, by the very structures that make reflection so difficult to accomplish. Despite these levels of complexity and the range of terminology used among theorists, some agreement on the process does exist. In one explanation of the reflective process, Boud, Keogh, and Walker (1985b) posit three stages: "Preparation, engagement in an activity, and the processing of what has been experienced" (p. 9). 
Another description is as simple as "What? So what? Now what?" (Barnett \& O’Mahony, 2006, p. 502). All versions, however, draw heavily on Dewey's work.

The reflective process starts when practitioners experience what Schön (1987) calls "surprise" when something doesn't work as planned. They analyze the situation and create a new plan of action, test that plan, and reassess their practice. Schön argues that experienced instructors often "correct" practice on the spot, using "reflection-in-action," and reassess their teaching after the fact, which he called "reflection-on-action."

According to Rodgers (2002), who offers a close reading and analysis of Dewey's most relevant scholarship, reflection is a meaning-making, educative process that involves the "intellectual, moral, and emotional growth of the individual, and, consequently, the evolution of a democratic society" (p. 845). Like most scholars of reflection, Rodgers outlines several criteria for determining if reflection is taking place, one of which is that true reflection does not take place in isolation. Dewey (1916) demanded what he called reflection-in-community: "One has to assimilate, imaginatively, something of another's experience in order to tell him intelligently of one's own experience" (pp. 6-7). Those who stress reflection as part of a larger, transformative process see the element of discussion with a larger community as crucial. Zeichner (1996), for example, argues that unless reflective teacher education promotes social justice, it should not be supported; it simply continues to isolate teachers in their own classrooms, where they become "technicians, not professionals" (p. 206).

For Dewey, "educative experience" involved interaction between a person and her environment-between the self and another person, an idea, or whatever else makes up the particular environment. This, in turn, would lead to what Dewey named "intelligent action," another criterion for reflection (Rodgers, 2002). In addition, reflective practitioners would have to be willing to experiment with various actions, paying close attention to the results of every new action they take.

This process is supported by certain attitudes in practitioners that Dewey believed are essential to genuine reflection: wholeheartedness, directness, open-mindedness, responsibility, and readiness. By wholeheartedness, Dewey meant a genuine enthusiasm about one's subject matter as well as curiosity about it. The second characteristic, directness, is freedom from self-absorption and the presence of a reasonable self-awareness. According to Rodgers, this is the difference between "What did I teach today?" and "Where was the learning in today's work?" (p. 860). Openmindedness, for Dewey, was "hospitality" to new ways of seeing and understanding. This concept included "playfulness," or releasing the mind 
to play with our ideas rather than clinging to them. Schön (1987) sees testing a hypothesis in a practical situation such as teaching as part of this playfulness.

Rodgers (2002) adds two other characteristics (pp. 962-963). The first, responsibility, means that we must examine the practical applications of our thinking and weigh them carefully. The second is readiness for the critical self-examination and possible changes that may result from deep reflection. To accomplish truly reflective practice as an instructor, then, is to commit to a time-consuming and challenging process of deep thinking and planned and assessed action.

\section{Study Scope and Methodology}

We formed a research group to undertake a qualitative study on IUP's RP program to determine its impact on (1) the teaching of past and present members of RP, (2) the students of past and present RP members, and (3) the overall professional life of present and past RP members, as well as to determine what RP activities had the greatest impact on past and present members and any other ways these members perceived RP to have had an impact. We sent a call to all past and present RP members soliciting voluntary participants in the study. Ultimately, twenty-two RP past and present members agreed to participate. Each volunteer completed a short demographic questionnaire and agreed to be interviewed by a member of the research team (see Appendix). All interviews were tape-recorded.

This methodology has its limitations for gathering participants. For one, the interviewees were unavoidably self-selected. As most researchers on reflection point out, the process is jump-started by faculty recognizing that something is awry in their practice. Faculty self-initiate into RP, and the most motivated volunteered for this project. In the future, we hope to interview those who have not participated in RP to find out why.

\section{Interview Questions and Analysis}

We also decided that at this time we would not ask focused questions about the process of reflection or ask for evidence of reflection. We wanted to begin with general questions and apply criteria for reflection to those answers. Thus, participants had as much time as they needed to respond to these questions:

- What impact, if any, has participation in RP had on your teaching?

- What impact, if any, has participation in RP had on your students? 
- What impact, if any, has RP had on your overall professional life?

- Which activities in RP have had the most impact on you? In what ways?

- Are there any other comments you would like to share about RP?

The recorded interviews were transcribed, and we began the qualitative analysis of each transcript using grounded theory. An inductive approach, grounded theory requires researchers to break data into units of information that can then be categorized and subcategorized to define the boundaries of the larger categories. A narrative of sorts is created as categories are compared, contrasted, and sorted repeatedly, and finally central or master categories are selected and used to generate a theoretical model (Strauss \& Corbin, 1998). In our study, our research team independently analyzed each transcript, looking for themes. Then we all met to compare perceptions and develop a working consensus. Finally, we looked for the varying prominence of the common themes among all of the interviews. We counted references in a theme according to the number of times an interviewee mentioned it. So if a person made a comment within a particular theme four times during an interview, each time was counted separately. We then tallied the frequency of the overarching themes, as shown in Table 20.1. The total number of comments per theme includes both positive and negative ones.

Table 20.1. RP Themes Ranked by Frequency of References in Interviews

Themes

Collegial relationships

Changed teaching methods

RP effects on students

Inspiration

Personal growth

Overcoming complacency

Professional growth

Faculty feedback

Faculty collaboration

Reflection about self as teacher/learner
Frequency

58

50

23

21

21

20

18

17

16

15 


\section{Evidence of Reflection}

We also examined the transcripts for evidence of reflection using Rodgers's expanded criteria for reflective practice as touchstones (2002): wholeheartedness, growth, directness, open-mindedness, responsibility, analysis of experience, intelligent action, and inquiry-in-community. We coded the transcripts simply: "yes-clear statement matching criterion"; "no-no statement matching criterion"; or "implied—statements taken together indicate that the criterion has been met, though a direct and supportive statement is not evident." We did not tally the number of yes, no, or implied statements. If, for example, a participant repeatedly expressed a need for developing new skills, we counted them together as evidence of a desire for growth (see Table 20.2).

This portion of the coding was particularly frustrating. We are familiar with the teaching practices and philosophies of our colleagues and knew, for example, that they had taken "intelligent action" in past situations, but we decided that we could work only with what they actually said during the interview. Our interview questions in future research will close this empirical gap.

\section{Findings: The Faculty Needs That RP Met}

The themes we discerned in the interviews helped us identify three driving needs that RP was meeting. This information will help us both recruit new participants who have needs and goals consonant with what our

Table 20.2. Frequency of Statements in Interviews Supplying Evidence for Reflection

\begin{tabular}{lccc} 
Criteria for Reflection & \multicolumn{3}{c}{ Evidence of Reflection } \\
& Yes & No & Implied \\
Wholeheartedness & 18 & 3 & 3 \\
Growth & 21 & 0 & 1 \\
Directness & 16 & 4 & 2 \\
Open-mindedness & 19 & 1 & 2 \\
Responsibility & 16 & 3 & 3 \\
Analysis of experience & 14 & 1 & 7 \\
Intelligent action & 16 & 1 & 5 \\
Inquiry-in-community & 22 & 0 & 0 \\
\multicolumn{2}{c}{ Note: Total N of participants $=22}$. &
\end{tabular}


program can offer and also use our resources more carefully to shape future program offerings.

\section{The Need to Connect}

Not surprisingly, the most important participant need met by our RP program was collegiality. In RP, members said they found safety, security, and friendship. Unlike in most educational contexts, they could admit that they were struggling with teaching without getting a "black mark" on their formal or informal record. Because the goal of RP was teaching improvement, talking about their struggles was not an admission of failure but a first step toward becoming a better instructor.

Faye (all names of interviewees have been changed) explained how the safety of her small group allowed her to work deeply on her teaching: "It made me real transparent in some real interesting ways. I could say, 'I did this thing, and God, did it backfire. Have you tried this? How did it work?'" Many participants also mentioned the support, the validation of knowledge and accomplishment, and the sense of being valued that the program afforded.

RP participants also recounted the fun, excitement, passion, connection, and self-esteem they experienced in the program. Though Tony listed his many pedagogical changes and claimed the RP workshops "revolutionized" his teaching, he maintained, "I really value the social stuff more." After a presentation to the large group, he reflected: "People are coming up saying 'That's fantastic,' or 'I really value that' and I think, to me, when I see someone else get up and give a speech, I think, 'Wow, that's another great person doing great stuff, and I try to convey that to them.'"

\section{The Need to Learn}

RP members valued continued growth and change in teaching, which is probably why they self-selected into the program. Not surprisingly, the category of "changed teaching methods" ranked almost at the top of the list, and many other categories supported the importance of "good teaching." Excitement and passion about learning drew us into our careers and kept us going to become professors, and most of us expect to stay in the field for a very long time. The fear of stagnation was a driving force in RP participation: overcoming complacency ranked sixth on the list, with twenty references. At IUP, where the teaching load is high and the range of student skills in each class is great, faculty must incorporate a variety of pedagogical techniques to engage, educate, and-some would say-entertain their students. Further, in the cultures of some disciplines, 
many lower-level courses lack time for exploration and tentativeness. Conflict between disciplinary and student expectations can create a pedagogical tension that must be resolved, perhaps the initiating "surprise" in the process of reflection.

In these interviews faculty make frequent references to "newness," to change, to learning. In lives that are usually defined by the pursuit of knowledge, people eagerly seek structures that support learning. Nancy, for instance, recalled that lecturing to a large class was always the norm. She had been lectured to as a student in the sciences and followed that pattern with her own students in her own large classes. When she at last experienced a small class, she was happily surprised by how her students asked questions and engaged in discussion. Shifting back to a large lecture section, she knew she had to change her teaching to generate student participation: “The students were much more reserved. It just didn't feel right. Reflective practice was the first formal opportunity to reflect on how I taught and what I could do differently."

\section{The Need to Leap Boundaries}

The cross-disciplinary nature of RP was also an important draw for many of the participants-a significant subcategory within both "collegiality" and "knowledge gained through RP." Regardless of their discipline, members wanted to know how other disciplines approached teaching problems, even if what they learned was disconcerting. As Louise noted, "There's a tendency to stay where you are and communicate with the people who are in the same area you are in. ... I've gotten to know people from other areas, to see ideas that are completely different, philosophies that are different."

Another participant, Alice, acknowledged the challenge of moving between disciplines: "I gained an understanding of what it means to be in another discipline. ... It's disturbing to go out of your zone." This reaction echoed Johansson and Kroksmark's observation: "Teaching actions that harmonize with our own attitude give us a sense of security, especially if they coincide with the hidden attitude (towards the learner, school, knowledge, work methods, etc.) constituting the pedagogical nature of the schools. It is the other way around if the teacher is forced into teaching actions which are not his own" $(2004$, p. 367).

The interdisciplinary contact that RP encouraged facilitated participants' quest for a new perspective, another angle from which to approach a pedagogical problem. In such a safe environment, they experienced no threat. Rather, moving across disciplines led not only to new friendships 
among many RP members but also to new knowledge, which enhanced their sense of themselves as learners as well as teachers.

\section{The Degree of Reflection}

Of crucial importance to us was to determine whether RP was actually promoting reflection among members. Chism, Lees, and Evenbeck (2002) argue that, as we move from teacher-centered teaching to student-centered learning, we come to realize that we can't focus on technique but must be scholars of teaching and learning: "Instead of relying primarily on 'tips' and workshops that model effective techniques, those involved in the work of faculty development have come to operate on the principle that cultivating intentionality in teaching is at the heart of their work. . . The concept of faculty development that emerges is based on community activity that depends on constant reflection to assess results and reconceptualize strategies" (pp. 34, 36).

The combination of a high number of references to changes in pedagogy (fifty) and a relatively low number of references to reflection about self (fifteen) might lead readers to believe that participants in RP were not particularly “reflective" by Dewey's and others' formal definitions. We might initially perceive them as merely "tinkering," as one participant put it. For some RP members, the demands of teaching, research, and service at any given time may mean all they feel they can accomplish is tinkering. These numbers, however, are part of a bigger picture.

We saw in our coding that RP participants were attending workshops and meeting with colleagues because they had identified a problem connected to teaching, were making changes as part of a longer process of discussion and learning, and were developing teaching and reflection skills within a community of like-minded colleagues. They were not simply looking for tips; they were seeking tips that supported a process of effective, long-term change.

Many interviewees recounted how participation in a small group or a workshop changed their teaching fundamentally. Nancy referred to a teaching philosophy statement she had revised since her involvement in RP: "I think about what it is I really like about teaching, and I go back and read it all the time." Tony pointed out that although he changed many small things (tinkering and tips) because of RP, more importantly, "I started saying 'I have these core things I believe' and I'm trying to structure the unit so they are aimed toward these things. That has taken me quite a while... to revamp the whole course takes a lot of thinking." 
Making quick changes based on workshop ideas takes relatively little work; reflection and change are much more difficult. This may account for why collegiality, feedback from colleagues, and support also appeared high on the list.

\section{Assessment: A Missing Link in the Reflective Process}

Many RP participants pointed to specific changes, but few were able to say whether these changes were "working"-that is, improving their teaching and their students' learning. Jane declared: "If nothing else, I feel better about what I'm doing, and if I feel better about what I'm doing, then I have every reason to believe I'm doing it more efficiently and trying new things and doing it better. Even if my students don't believe that, I do."

When asked how his participation in RP has had an impact on his students, Paul admitted, "I don't know how I tell that." He continued, "I think overall the impact has been a very positive one, because I think my teaching has improved."

The RP program has sponsored many workshops on assessing student learning. How, then, can we make sense of these statements? Perhaps Paul and Jane were not thinking about student learning outcomes in any conventional use of the term. Attending workshops, thinking about our teaching, drafting teaching philosophy statements, tinkering with courses, and the like make us feel good about ourselves as instructors-more effective, more competent. Participation in RP is not always so much about student learning outcomes, at least not on a deep, personal level. The focus may be inward, and the participants' sense of professional self may change. This is a good place to start, but we cannot stop there. Reflective practitioners must also move outward. Feeling good inside does not necessarily equate to effective teaching.

Participants did occasionally reference informal assessment. Ed indicated that after he instituted humor in the form of cartoons to begin each class, one student brought in a cartoon for him to use. Tony said he received some letters saying how much students liked a particular aspect of his teaching. Still, Ed admitted that he didn't "monitor student responses in the classroom all that much," and Tony has many other students who don't write him letters. Evidence of carefully structured assessment of new course elements and teaching techniques was distinctively lacking in these interviews.

\section{Culture and Community: An Area of Dispute}

Dewey strongly argued that changes must move beyond the insulated community of the classroom to the larger culture. Thus the low number of references to changes in the campus culture (ranked twelfth) as a 
result of the RP program was of interest to the researchers. But our participants did not necessarily agree with Dewey about how widely the net should be cast to create a community of reflection. Anita, one of the long-time RP members in this study, pointed out that initially RP was about being dedicated to teaching and excelling at it, and the small number of faculty who joined the program formed a tightly knit group that was "hell-bent" on improving. In fact, these founders were largely senior faculty: "[We were] looking at those colleagues particularly who are called 'deadwood' and trying to put fire under them and keep fire under us so that we would not lose enthusiasm for our profession." She expressed concern over the larger number of faculty currently involved in RP and their motives-that the larger numbers make a close-knit community difficult to create, and that the newer members might just be going for promotion and could be only "paper participants." Although many program administrators would see increasing numbers as a positive sign of cultural change on campus, it is also possible that more negative aspects of the university teaching structure-the overwhelming need for tenure and the competition for promotion-might be infiltrating, warping, and undermining the structure and goals of reflective practice.

Participants mentioned RP's effects on their students relatively often, but they did not necessarily understand, measure, or appreciate those effects. For example, Nancy bemoaned her students' complaining about her forcing them to take an active role in their learning. In addition, given the structure of most students' programs, these effects might have been highly localized. Faculty in midsized institutions such as IUP or larger ones may not get the opportunity to work closely with the same students over a period of years. Many students take an instructor only once, particularly in large departments; for nonmajors, that professor is likely teaching an introductory level course. So RP's impact on teaching and the student population at IUP is currently very difficult to assess.

However, the knowledge that faculty gained by reflective practice did change a smaller community, especially in the case of the teaching circles. Jane reported that her departmental teaching circle "opened up more communication between my colleagues and myself." Hilda said that her involvement in a cross-disciplinary teaching circle made her question how her own department handles teaching "because there are other ways to think about how to teach and how students learn." The group's protection from administrators' participation and the unwritten confidentiality rules fostered this open sharing. Unfortunately, they also prevented the knowledge gained from going beyond the limits of the group. 


\section{The Bottom Line: Is RP Creating Reflective Practitioners?}

The findings indicate that, even given the broad interview questions, all the participants clearly demonstrated some level of reflection on their teaching, and many clearly demonstrated it in all categories. In addition, it appears that the combination of safe structures in which faculty can explore their teaching and many opportunities to work across disciplines fosters reflection. However, in the categories of directness, responsibility, analysis of experience, and intelligent action, we saw mixed results. We recorded few mentions of assessing the impact on students of changes to teaching, so the category of "responsibility" had a fairly high number of "no" or "implied" responses. We have no reason to believe that our participants were weak on directness-that is, the ability to analyze the teaching experience from multiple perspectives-but our broad questions did not ask them to do so. In future interviews, we hope to get a clearer picture of where RP members struggle most as they become reflective practitioners and alter the program to address those struggles.

\section{Future Research and Actions}

The questions that drove us initially were why faculty participated and whether our RP program actually encouraged and supported their reflective practice. If we further explore RP's impact on participants, we will likely select a smaller number to interview and revisit the most interesting and frustrating elements of the initial interviews. We believe that "made changes in pedagogy" entails some of the assessment that faculty did not articulate in the more general interviews we conducted. Asking targeted questions that break out various elements of teaching-for example, asking about specific kinds of assessment techniques rather than a general question-would likely prompt more detailed answers regarding reflection and practice. We also intend to survey some of the faculty who do not participate. What tips the balance for them, making them decide not to take up the invitation, not to go to the workshops, and not to join a small group inside their department? Many scholars observe that institutional structures overwhelmingly support and encourage isolation in the classroom. As Cochran-Smith and Lytle (1996) put it, "Isolation . . makes for privacy as well as loneliness, autonomy as well as separation" (p. 96). Perhaps some colleagues value their privacy and autonomy so much that the communal nature of reflective practice appears threatening to them. So they will endure loneliness and separation in order to maintain the control they feel they exercise. Perhaps they are introverts who practice reflection on their own, skipping its communal aspects. 
Duffy (2008) doubts this, however, arguing that "reflection should not be a lone activity if real learning is to take place” (p. 334). But Duffy's may be too dogmatic an approach to reflective practice. Only by interviewing non-RP colleagues will we begin to understand their reluctance to join the RP program.

We also recognize that, if reflective practice programs want to meet participants' need to learn, workshops cannot simply be repeated. Advanced levels must be offered, or senior participants will find their needs are not being met. Structures to support cross-disciplinary pedagogical exchange must be designed and promoted across campus.

Qualitative research such as ours generates questions, narratives of "how things work" in a particular context that allow comparison and contrast. We hope that the coordinators of other reflective practice programs will begin to look carefully at their members' motivations, concerns, and changes as we have done here. In a culture rapidly embracing a business model, we need a clear understanding of the benefits of spending —and spending wisely-monies and time on reflective practice as part of a larger program of professional development. When we can create the structure that makes reflective practice the norm, hopefully faculty will not simply survive academe but will thrive. 


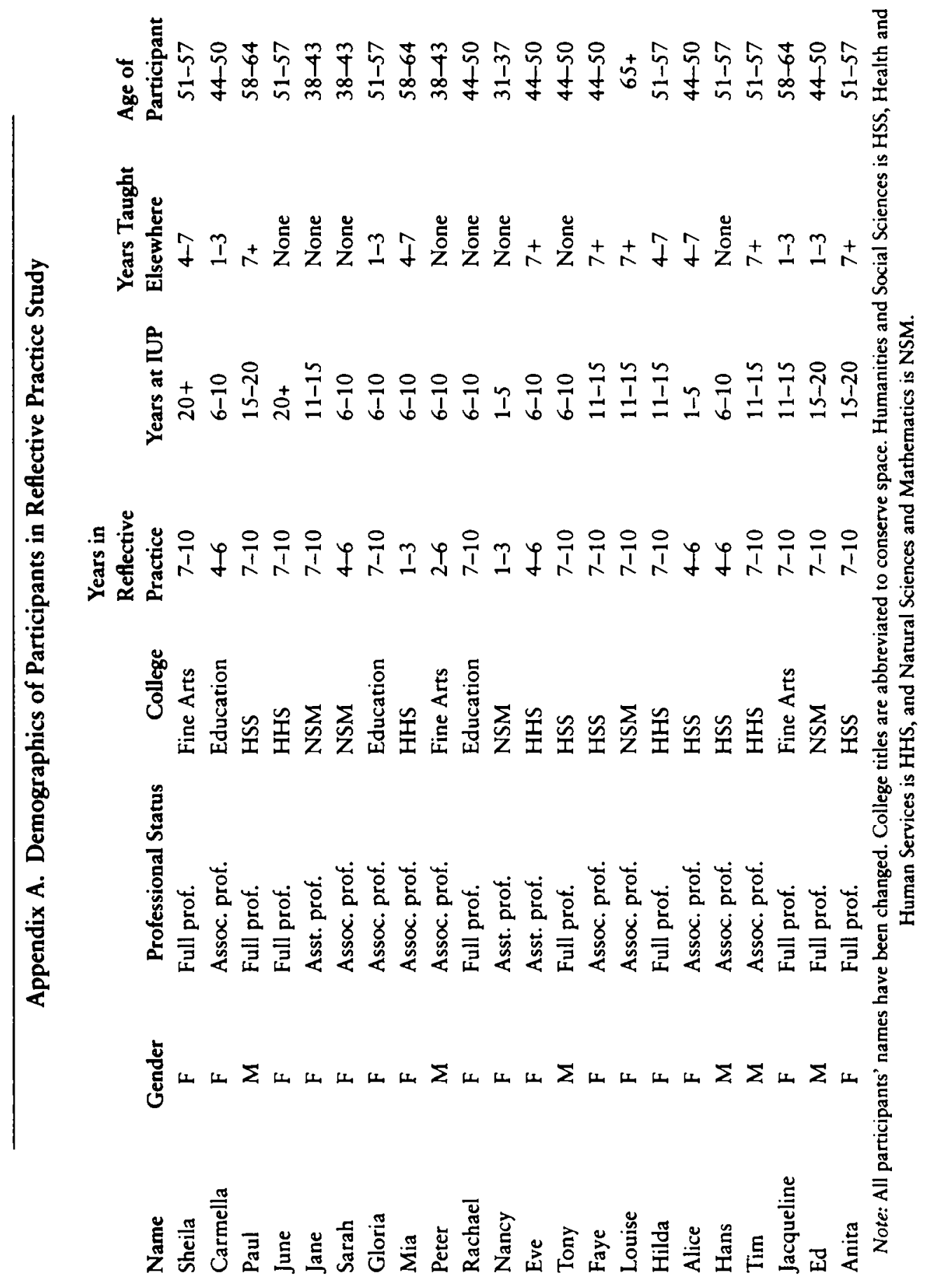




\section{REFERENCES}

Barnett, B. G., \& O'Mahony, G. R. (2006). Developing a culture of reflection: Implications for school improvement. Reflective Practice, 7(4), 499-525.

Black, L. J., Cessna, M. A., \& Woolcock, J. (2005). The reflective practice project: Faculty production beyond the numbers. In J. E. Groccia \& J. E. Miller (Eds.), On becoming a productive university: Strategies for reducing costs and increasing quality (pp. 149-157). Bolton, MA: Anker.

Boud, D., Keogh, R., \& Walker, D. (1985a). Promoting reflection in learning: A model. In D. Boud, R. Keogh, \& D. Walker (Eds.), Reflection: Turning experience into learning (pp. 18-40). New York: Nichols.

Boud, D., Keogh, R., \& Walker, D. (1985b). What is reflection in learning? In D. Boud, R. Keogh, \& D. Walker (Eds.), Reflection: Turning experience into learning (pp. 7-17). New York: Nichols.

Chism, N.V.N., Lees, N. D., \& Evenbeck, S. (2002). Faculty development for teaching innovation. Liberal Education, 88(3), 34-41.

Cochran-Smith, M., \& Lytle, S. L. (1996). Communities for teacher research: Fringe or forefront? In M. W. McLaughlin \& I. Oberman (Eds.), Teacher learning: New policies, new practices (pp. 92-112). New York: Teachers College Press.

Dewey, J. (1916). Democracy and education. New York: Free Press.

Duffy, A. (2008). Guided reflection: A discussion of the essential components. British Journal of Nursing, 17(5), 334-339.

Fullan, M. (1993). Change forces: Probing the depths of educational reform. New York: Falmer.

Johansson, T., \& Kroksmark, T. (2004). Teachers' intuition-in-action: How teachers experience action. Reflective Practice, 5(3), 357-381.

Korthagen, F. A. (1993). The role of reflection in teachers' professional development. In L. Kremer-Hayon, H. C. Vonk, \& R. Fessler (Eds.), Teacher professional development: A multiple perspective approach (pp. 133-146). Berwyn, PA: Swets \& Zeitlinger.

Lieberman, A. (1996). Practices that support teacher development: Transforming conceptions of professional learning. In M. W. McLaughlin \& I. Oberman (Eds.), Teacher learning: New policies, new practices (pp. 185-201). New York: Teachers College Press.

McKinnon, A. M., \& Grunau, H. (1994). Teacher development through reflection, community, and discourse. In P. P. Grimmett \& J. Neufeld (Eds.), Teacher development and the struggle for authenticity: Professional growth and restructuring in the context of change (pp. 165-192). New York: Teachers College Press. 
Mezirow, J. (1990). How critical reflection triggers transformative learning. In J. Mezirow (Ed.), Fostering critical reflection in adulthood: A guide to transformative and emancipatory learning (pp. 1-20). San Francisco: Jossey-Bass.

Rodgers, C. (2002). Defining reflection: Another look at John Dewey and reflective thinking. Teachers College Record, 104(4), 842-866.

Rogers, R. (2001). Reflection in higher education: A concept analysis. Innovative Higher Education, 26(1), 37-57.

Schön, D. (1987). Educating the reflective practitioner. San Francisco: Jossey-Bass.

Sparks, D., \& Hirsh, S. (1997). A new vision for staff development. Oxford, $\mathrm{OH}$ : National Staff Development Council.

Strauss, A., \& Corbin, J. (1998). Basics of qualitative research: Grounded theory procedures and techniques. Thousand Oaks, CA: Sage.

Szabo, M. (1996). Rethinking restructuring: Building habits of effective inquiry. In M. W. McLaughlin \& I. Oberman (Eds.), Teacher learning: New policies, new practices (pp. 73-91). New York: Teachers College Press.

Wagner, K. (2006). Benefits of reflective practice. Leadership, 36(2), 30-32.

Zeichner, K. (1996). Teachers as reflective practitioners and the democratization of school reform. In K. Zeichner, S. Melnick, \& M. L. Gomez (Eds.), Currents of reform in pre-service teacher education (pp. 199-214).

New York: Teachers College Press. 